\title{
The Effect of Recognize Favor Standard on Customer Faithfulness in IT Sector
}

\author{
Subhadra Ray \\ Dept. of Social Work, Christ College, Bangalore
}

\begin{abstract}
:
This study is done to analyze the Effect of Recognize Favor Standard on customer Faithfulness in IT sector of India. Parasuraman in his initial study carried out in determined five dimensions which became base for the measurement of Recognize Favor Standard. Recognize Favor Standard is deemed to be independent variable while customer Faithfulness was treated as a dependent variable. The later could however be measured by 13 items which was previously proposed by Zenithal. (Reliability, empathy, competence of staff, accessibility and tangibles are the key factors that best explain customer's expectations. A SERVQUAL scale was used to measure Favor Standard perceptions from the perspective of domestic and international customers. Data were collected in 15 outlets of IT Favor providers, using a self-administered questionnaire. Descriptive statistical analysis, exploratory factor analysis and reliability analysis were conducted. This study reveals that the expectation level of customers is very high towards Favor Standard. Thus, the findings can be used as a guide for IT industry to improve the Standard attributes and enhance Favor Standard and business performance which in turn will improve the trust and Faithfulness of customers. More specifically, it is found that the empathy dimension is the strongest predictor of customer Faithfulness.
\end{abstract}

Keywords: Recognize Favor Standard, Customer Faithfulness, SERVAQUAL, Factor analysis, Reliability analysis, Internet Favor Providers.

\section{Introduction}

A Favor is a set of singular and perishable benefits delivered from the accountable Favor provider, mostly in close coactions with Favor suppliers, generated by functions of technical systems and by distinct activities of individuals according to the needs of Favor consumers [14]. Studies reveal that the contribution of the Favors sector to the Indian economy has been assorted 55.2 per cent share in gross domestic product (GDP), growing by 10 per cent annually, causative to about a quarter of total employment, accounting for a high share in foreign direct 
investment (FDI) inflows. India continues to be the dominant player in the global outsourcing sector. However, its future will depend on how the challenges related to its continued competitiveness are tackled. These include increasing competition, rising costs, talent shortfall, infrastructure constraints, increasing risk perception, protectionism in key markets, and deteriorating business environment. IT and IT sector added laurels to India by gaining a brand identity as a knowledge economy. The IT industry has four major components: IT Favors, business process outsourcing (BPO), engineering Favors and R\&D, and software products. The growth in the Favors sector in India has been led by the IT-IT sector which has become a growth engine for the economy, contributing substantially to increases in the GDP, employment, and exports. This sector has improved its contribution to India's GDP from 4.1 per cent to 6.1 per cent and an estimated 6.4 percent.

\section{IT industry and software contribution towards Indian Favor Economy:}

The Indian software industry is mainly export-oriented. The industry garners around 60-70 per cent of the total revenue from its two largest markets, namely the US and Europe. The economic slowdown in these major export destinations led to a deceleration in growth of sales of the Indian software industry to 5.9 per cent. However, sales are expected to grow at 16.9 per cent and 17.8 per cent, respectively during and due to higher client additions and an uptick in billing rates.

\section{Internet and Broadband:}

The Internet, which is another growing mode of communication, is a worldwide system of computer networks. Broadband is often called 'high speeds Internet, because it usually has a high rate of data transmission. Broadband subscribers grew from 0.18 million to 10.71 million as at the end of November. The number of Internet and broadband subscribers is expected to increase to 40 million and 20 million, respectively. Introduction of BWA (Broadband Wireless Access) Favors will enhance the penetration as well as growth of broadband subscribers. Wi Max has also been making headway in penetration of wireless broadband connectivity across all sectors. It was revealed in a research that $75 \%$ of the internet audience in India to be aged 35 years and below, promising to make it the youngest online population in the coming years. Females formed $39.3 \%$ of the total audience, and the sharpest growth was observed among male and female segments in the age-group 15 to 24. Indeed, the Standard of Favor is sometimes more important for customers than the cost of acquiring that Favor. Thus calls a need for the organizations to focus on providing customers with the highest possible level of 


\section{INNOVATIONS}

Standard. Based on past experiences brand image, word-of-mouth communication and proper evaluation of their own needs, customers create expectations of the Favor which they are willing to purchase. SERVQUAL, the 22-item scale developed by Parasuraman is considered one of the most widely used instruments in the measurement of Favor Standard [4] and is based on fives dimensions

- Tangibles: physical facilities, equipment, and appearance of personnel.

- Reliability: ability to perform the promised Favor dependably

- Responsiveness: willingness to help customers and provide prompt Favor.

- Assurance: knowledge, courtesy of employee, ability to inspire trust and confidence.

- Empathy: caring, individualized attention that the firm provides its customers.

\section{Research Methodology}

\section{Population, Sample, and Data Collection}

The population of this study consists of internet subscribers. Indeed, the data was mostly filled by the VSNL and BSNL subscribers who were found out in premises of these offices and internet subscribers as they came to pay their bills at its different sales shops. VSNL has huge list of subscribers and authenticity of data from such sources is most acceptable. It was difficult to have access to information (e.g. emails or mobile numbers) that could help in contacting or reaching customers because of privacy and security issues. Moreover, the sample size for a population consisting of 291067 subscribers must be 384.500 questionnaire were distributed out of which number of questionnaires returned was 443 and 420 were found to be valid.

\section{$\underline{\text { Measures }}$}

The research is quantitative in nature. The items selected to measure the concepts of Recognize Favor Standard and customer Faithfulness were primarily derived and taken from literature. Recognize Favor Standard was measured using five dimensions (tangibles, reliability, responsiveness, assurance, and empathy) of SERVQUAL. The Recognize Favor Standard was measured using a five-point rating scale rating from one: 'strongly disagree' to five: 'strongly agree'. 


\section{Data Analysis}

In order to examine the research hypotheses, the data collected through the questionnaire distributed to the customers were analyzed.

\section{$\underline{\text { Respondent's Profile }}$}

The respondents for this study were asked to give information about their gender, age, education level, and family status. The data reveals number of male is more than female which imply that men use internet more. There is no significant Effect or marital status of respondents as both have similar fashion of using internet and probably time of using in both types of respondents affects [12] less.

\section{Hypothesis Testing}

Research study was started by multi-co linearity diagnosis for testing hypothesis which was done using Variance Inflation Factor (VIF) and tolerance value. The tolerance values range between 0.4 and 0.5 which are above 0.2 . This suggests that the hypothesis does not suffer multi-co linearity problem in the regression model. The results as shown in table are all below 0.75 and thus do not suggest high correlation between the variables.

\section{Conclusion}

The fast growing world and excessive contribution of Favor industry in our economy compels us to satisfy the customer. This however could be done if Favor provider understands the perceptions [17] of customers because it relates strongly to the continual survival, as well as the future growth and development of organizations. The results of multiple regression analysis shows that Recognize Favor Standard [8] dimensions have a important Effect on customer Faithfulness.

\section{Applications}

This study enables others to recognize the effect of Recognize Favor Standard on customer Faithfulness in ISPS in India. Since availability of data was limited so efforts were done that study may not deviate the field and may not get affected but the available survey reports of other countries. In addition multidimensional perspective was also taken into count during study of customer perception of Favor Standard and Favor Faithfulness [6]. In addition to the theoretical development, the findings further can be utilized for the expansion and 
implementation of practices that will lead to loyal customers. This may help corporate decision makers in an exact evaluation of Favor Faithfulness and optimization of allocation of resources. This enables managers to be aware of how customer perception of Favor Standard affects customer Faithfulness and then identify the characteristics of these effects.

\section{Limitations and Recommendations}

Since the population of this analysis is very huge, the data were not easily available and it was tough to have access to information that could help in contacting or getting specific customers because of solitude and safekeeping issues. Therefore, this study used convenience sampling, and this might lead one to question the ability to generalize the findings. Thus, for future researches probability sampling technique like stratified random sampling techniques are recommended. Thus due to similarity of the ISPs' procedure, purpose, Favors provided and the same organizational and cultural environment allows for the possibility that the results of this study can be further utilized to other ISPs in India. Since the results of this study are based on customers' perceptions of Favor Standard only, future researches should investigate the comparison between customers' and Favor providers' perceptions of Favor Standard.

\section{References}

[1] Afsar, B., Rehman, Z.U., Qureshi, J.A., \& Shahjehan, A. Determinants of customer Faithfulness in the banking sector: The case of Pakistan. African Journal of Business Management.

[2] Bloemer, J., Ruyter, K., \& Wetzels, M. Linking Recognize Favor Standard and Favor Faithfulness: A multi-dimensional perspective. European Journal of Marketing .

[3] Chiou, J.S. The antecedents of consumers' Faithfulness toward internet Favor providers. Information and Management.

[4] Cronin jr., J.J., \& Taylor, S.A. SERVPERF versus SERVQU QUAL: Reconciling performancebased and perceptions-minus-expectations measurement of Favor Standard. Journal of Marketing,

[5]Fitzgibbon, C., \& White, L. The role of attitudinal Faithfulness in the development of the customer relationship management strategy within Favor firms. Journal of Financial Favors Marketing, 
THE AMERICAN JOURNAL OF

SOCIAL SCIENCE AND EDUCATION

VOLUME01 ISSUE01 INNOVATIONS 